\title{
STUDY OF FLEXURAL BEHAVIOR, THERMAL VARIATION AND LUMINOSITY TEST ON FILLER SLABS
}

\author{
Abhishek. $\mathbf{P}^{\mathbf{1}}$, Mohammed Zakiulla ${ }^{2}$, K Srisha Rai $^{3}$ \\ ${ }^{1}$ PG student, Dept. of Civil Engineering, K. S. School of Engineering and Management, Bengaluru, Karnataka \\ ${ }^{2}$ Assistant Professor, Dept. of Civil Engineering, K. S. School of Engineering and Management, Bengaluru, Karnataka \\ ${ }^{3}$ Assistant Professor, Dept. of Civil Engineering, K. S. School of Engineering and Management, Bengaluru, Karnataka
}

\begin{abstract}
Due to rapid urbanization, there is an increase in demand of residential and commercial buildings which results in greater use of cement for construction thereby depleting the environment. The exces sive usage of cement has led to the implementation of greener approach in building construction. Filler slab is an environment friendly, alternative building technology which is being used in the present era. Filler slabs reduces the amount of concrete use d as certain amount of concrete in tension zone of the slab is replaced by the filler materials. In this study PET bottles and coconut shells are used as fil ler materials. Polyethylene terephthalate (PET) bottles which are dumped after being used take a lo ng time to degrade thereby affecting the environment. Coconut shell provides good thermal insulation and is also a waste product obtained from coconut trees. Since both the waste materials are inert, light in weight, they qualify to be a good filler materi al in the slab. The flexural behavior of conventional slabs and filler slabs are studied and it was seen that filler slabs withstood lesser load than that of conventional slabs. Luminosity test is done to study the amount of natural light passing through the PET bottle when it is used as a filler material. Temperature distribution on concrete is done to study the thermal insulation provided by the coconut shell as filler material.
\end{abstract}

Keywords: Filler slab, coconut shells, PET bottles, flexural behavior, lux, temperature distribution, isotherms etc.

\section{INTRODUCTION}

In the present era, there is increase in demand of concrete for building construction due to urbanization. However, due to depletion of non-renewable resources, production of concrete is affected. Excessive usage of concrete leads to increase in $\mathrm{CO}_{2}$ production thereby causing global warming. Therefore, reducing concrete in building construction is one of the solutions to the mentioned problem. Hence to cater to the problem, an alternate building technology such as filler slabs is adopted. Filler slabs are the type of slabs where filler materials are used in the tension zone of slab as a partial replacement for concrete in that region. Since, concrete does not play any role in withstanding the load in tension zone, some portion of concrete can be replaced by the filler materials. The filler materials used should be inert, light in weight, uniform shape, economical and readily available. In this study, coconut shells and PET bottles were used as filler materials. Coconut shell has a good thermal insulation property. PET bottles are non-biodegradable and they take a long time to decompose. They are one of the most dumped materials which harm the environment. Due to their transparent property, they can be used to transmit natural light.

\section{LITERATURE REVIEW}

M.A.D Chougule et al., have carried out an experiment in which they have used filler materials which are economical, light weight, low grade materials like Mangalore tiles, thermo polis burnt clay bricks, hollow concrete blocks, stabilized mud blocks, clay pots etc. These materials were placed in the grids of steel reinforcement in the slab and study on energy consumption in manufacture and transport of alternate building material was done. It was seen that energy consumed in Mangalore tiles (227 MJ), Ferro concrete tile $(158 \mathrm{MJ})$, brick masonry roof $(575 \mathrm{MJ})$ was lesser than common RCC slab (730 MJ). This study gave scope for study of different parameters like durability and design optimization of different filler materials. [1]

D.Y. Osei has studied use of coconut shell as an aggregate in concrete. Coconut shell is a waste material obtained from coconut trees. The use of this material helps in preservation of natural resources and reduces the construction cost. Concrete mix ratio of 1:2:4 was used to cast 72 cubes with replacement of gravel with different percentages of coconut shells and these were subjected to compression test after 7 days, 14 days, 21 days and 28 days of curing. It was seen that characteristic compressive strength decreased with increase in percentage of coconut shells. $48 \%$ of cost reduction was obtained by using coconut shells as a replacement for gravel. The final conclusion was that on replacement of $19 \%$ of gravel with coconut shells, optimum compressive strength was obtained. [2]

Aditya Singh Rawat et al. have studied usage of PET bottles as a sustainable building material. Plastic is a major solid waste dump and are also non bio degradable. They cause pollution thereby affecting the environment and all life forms. Hence they are suggested to be used as a convenient structural material to contribute as a construction material. In this study, the PET bottles were used as a masonry element by filling the bottle with sand acting as a bottle 
brick. To this bottle brick, basic compression test was done. It was seen from testing 8 such bottles that, the compressive stress was found to be around $8.98 \mathrm{MPa}$ for a load of 1300 $\mathrm{kg}$. It was also seen that the bottle brick per unit was $12 \%$ cheaper than regular brick. [3]

M.K.A Khafaji has carried out experimental study of temperature distribution of high strength concrete exposed to fire flame. In this study, cubic models of size $0.15 \mathrm{~m} \mathrm{x}$ $0.15 \mathrm{~m} \times 0.15 \mathrm{~m}$ were casted and exposed to a heat of $400^{\circ} \mathrm{C}$, $600^{\circ} \mathrm{C}$ and $800^{\circ} \mathrm{C}$ in kilns. 3D mathematical models were made to determine temperature distribution over the concrete specimen. The temperature determined during the experiment was compared with the 3D mathematical model. The concrete element was divided into a number of grids and temperatures were measured at each intersecting points. It was seen that the mathematically obtained values and measured values were similar and the temperature gradient was high at the top and bottom surfaces of the concrete specimen. [4]

D. Sandanasamy et al, have studied natural lighting in green buildings. Advanced day lighting systems improve quality of light in indoor environment, planned use of natural light can eliminate carbon emission and reduce global warming. Some tools like nomograph and software like Lumen micro, super lite 2.0 have been used for daylight calculations. Different materials and techniques are adopted like exterior shading, glazing material, aperture location reflectance. One such case study was adopted in Karaikal district in Puducherry. It was observed that $35 \%$ of electricity was saved by using daylight. [5]

\section{MATERIALS AND METHODOLOGY}

\subsection{Materials Used}

\subsubsection{Cement}

Ordinary Portland Cement -43 Grade, has been used.

\subsubsection{Fine Aggregates}

M-sand passing through IS Sieve designation of $4.75 \mathrm{~mm}$ sieve has been used. The sieve analysis conducted and it confirms to Zone II as per the specifications of IS: 3831970 .

\subsubsection{Coarse Aggregates}

Coarse Aggregate of size $20 \mathrm{~mm}$ maximum and retained on IS Sieve Designation of $12.50 \mathrm{~mm}$ sieve has been used.

\subsubsection{Water}

In this present work the water used in design mix is potable water from the supply network system.

\subsection{Methodology}

The concrete mix design obtained was $1: 2.26: 2.75$. The test for workability was done using a slump cone and the slump obtained was $100 \mathrm{~mm}$. Cubes of dimensions $150 \mathrm{~mm} x$
$150 \mathrm{~mm} \times 150 \mathrm{~mm}$ with and without filler materials were casted to check the compressive s trength after 7 and 28 days of curing.

Conventional slabs of dimensions $1 \mathrm{~m} \times 1 \mathrm{~m} \times 0.125 \mathrm{~m}$ were casted having reinforcement of $8 \mathrm{~mm} @ 200 \mathrm{~mm} \mathrm{c} / \mathrm{c}$. Similarly filler slabs with coconut shells and PET bottles as filler materials of same design were casted. The filler materials were placed in the intermediate areas of steel reinforcements as shown in figure 1 and figure 2 .

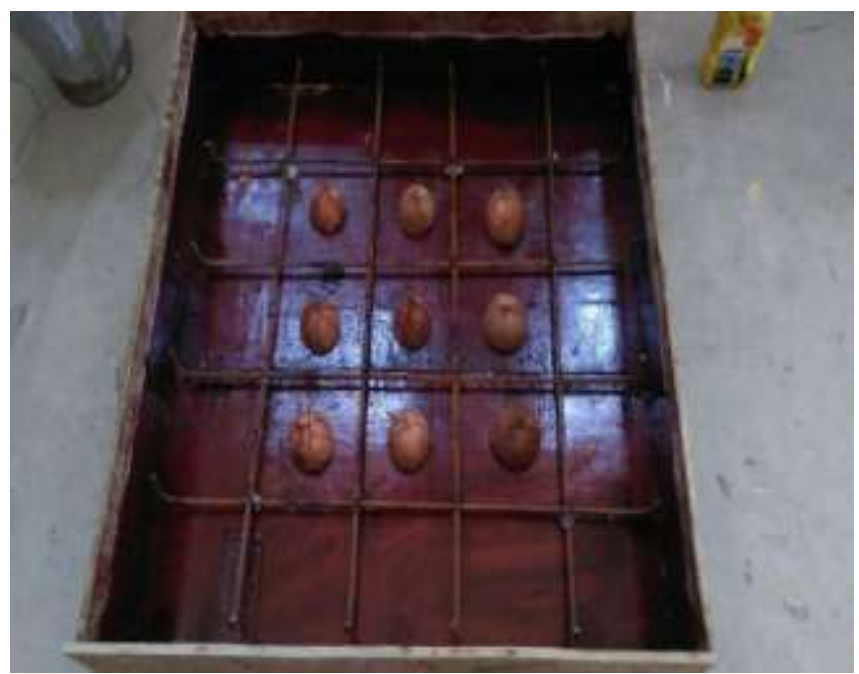

Fig 1: Coconut shell arrangement in filler slab

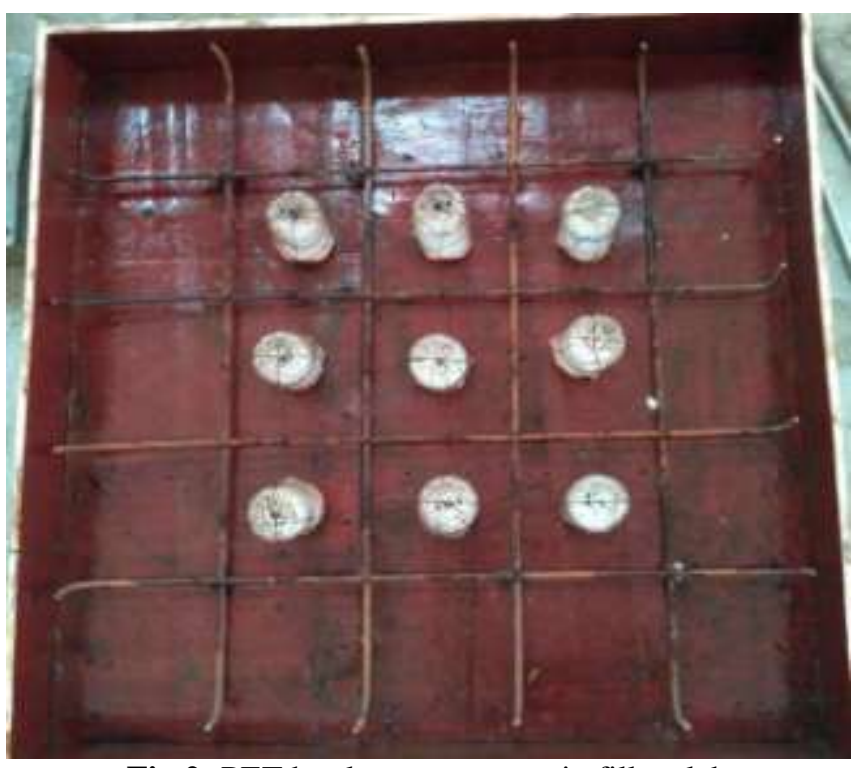

Fig 2: PET bottle arrangement in filler slab

\subsubsection{Setup for Flexural Test of Slab}

The flexural test on slabs was done using a loading frame having a capacity of 500 tons. The experimental setup consisted of the slab placed on the platform of loading frame with two steel I-sections placed on top of it. The hydraulic needle of the loading frame rested on the steel plate unit of depth $138 \mathrm{~mm}$ which in turn was placed perpendicularly on the I-sections. This arrangement led to 
two line load application system on the slab as shown in figure 3 .

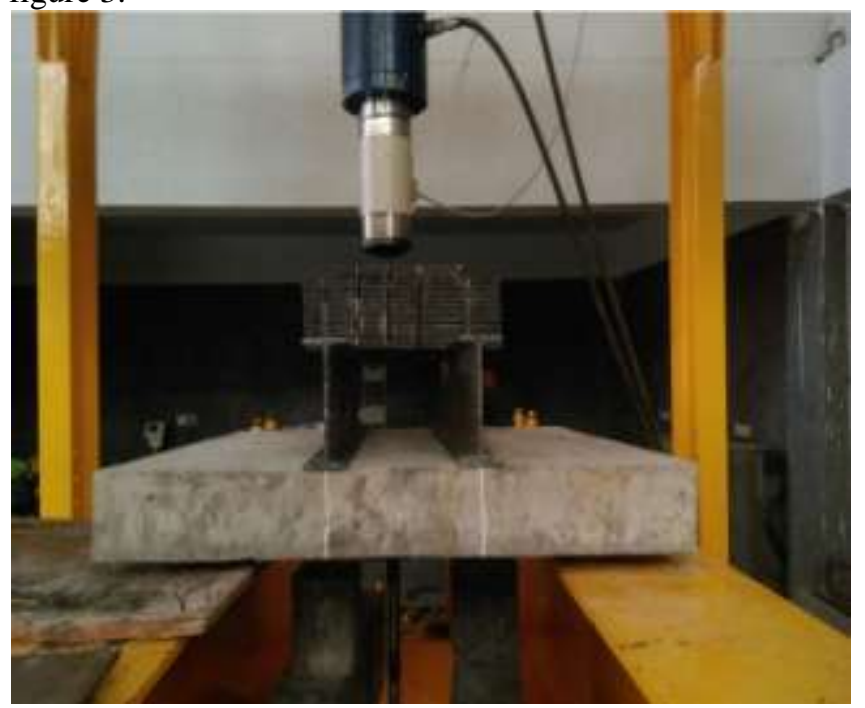

Fig 3: Experimental setup for flexural test

\subsubsection{Thermal Variation Test}

Blocks of dimension $0.2 \mathrm{~m} \times 0.2 \mathrm{~m} \times 0.125 \mathrm{~m}$ with and without coconut shell as filler were casted. The blocks were divided into grids of $0.05 \mathrm{~m}$ spacing. These blocks were subjected to a fire flame and the temperature readings at the intersecting grid lines were measured using laser gun. The isotherms for different temperatures were drawn in AUTOCAD.

\subsubsection{Luminosity Test}

Cube of dimension $0.2 \mathrm{~m} \times 0.2 \mathrm{~m} \times 0.125 \mathrm{~m}$ was casted along with a PET bottle placed at the center. A clear day was chosen to measure the luminosity of natural light passing through the filler cube. This was done by using Lux meter. The luminosity was measured in the form of lux and the readings were taken for different time throughout the day.

\section{RESULTS AND DISCUSSIONS}

\subsection{Compressive Strength of Cube}

Table 1 shows the mean characteristic compressive strength of cubes after 7 days and 28 days of curing.

Table 1: Mean compressive strength of cubes

\begin{tabular}{|l|l|l|}
\hline Type of cube & $\begin{array}{l}\mathbf{7} \text { days strength in } \\
\mathbf{N} / \mathbf{m m}^{\mathbf{2}}\end{array}$ & $\begin{array}{l}\mathbf{2 8} \text { days strength } \\
\text { in } \mathbf{N} / \mathbf{m m}^{\mathbf{2}}\end{array}$ \\
\hline Conventional & 20.9 & 25.5 \\
\hline Coconut shell & 16.2 & 21.5 \\
\hline PET bottle & 16.1 & 21.2 \\
\hline
\end{tabular}

\subsection{Flexural Test of Slabs}

The average load at which the conventional slabs yielded was found to be $38.9 \mathrm{kN}$ and the average displacement for 3 conventional slabs was found to be $1.41 \mathrm{~mm}$ as shown in chart 1.

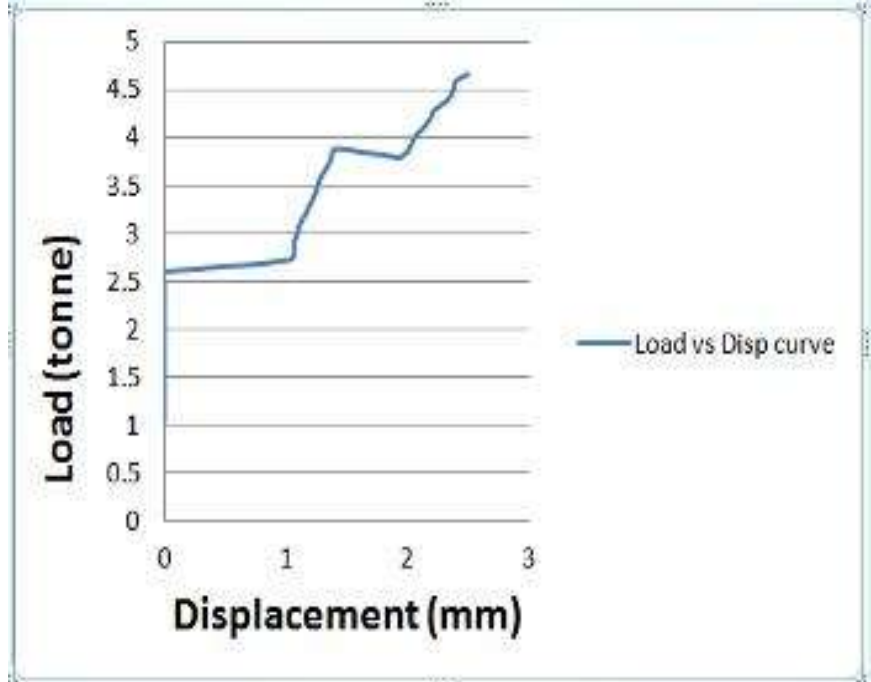

Chart 1: Load versus displacement curve for conventional slab

The average load at which the filler slab with coconut shell as filler material yielded was found to be $28.1 \mathrm{kN}$ and the average displacement for 3 filler slabs was found to be 2.04 $\mathrm{mm}$ as shown in chart 2 .

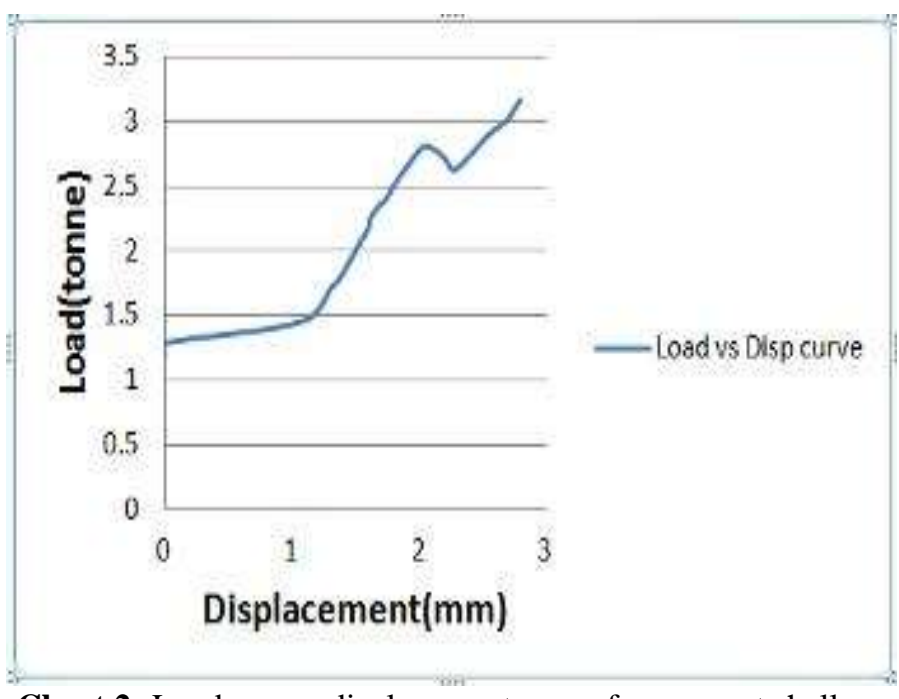

Chart 2: Load versus displacement curve for coconut shell filler slab

The average load at which the filler slab with PET bottles as filler material yielded was found to be $13.8 \mathrm{kN}$ and the average displacement for 3 filler slabs was found to be 1.42 $\mathrm{mm}$ as shown in chart 3 . 


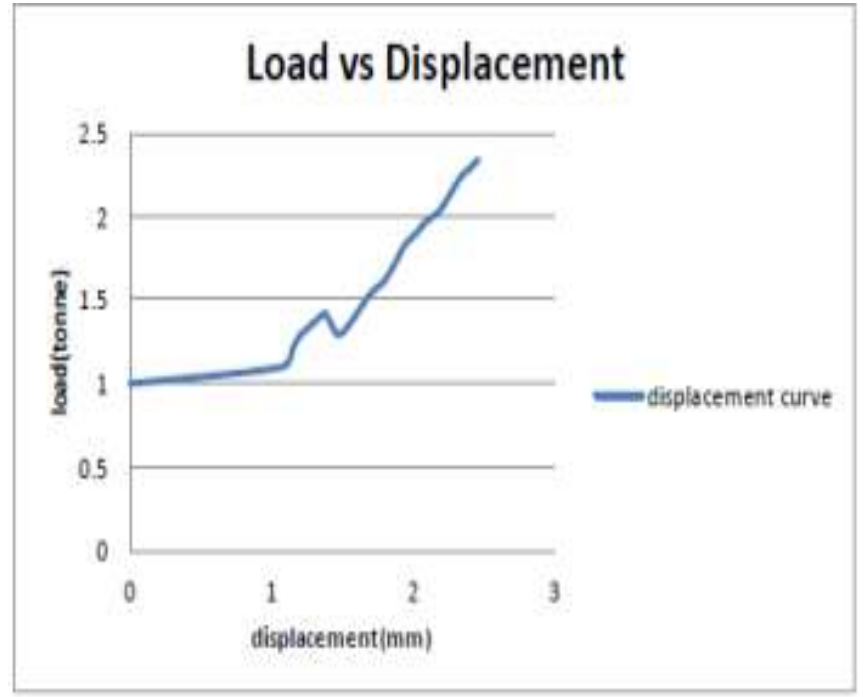

\subsection{Isothermsin Thermal Variation Test}

It is seen from figure 4 that heating the block for 15 minutes has increased the overall temperature of conventional block by $2.5^{\circ} \mathrm{C}$ to $5^{\circ} \mathrm{C}$. The initial temperature of the block was $28^{\circ} \mathrm{C}$. The temperature along the edges was found to be $45^{\circ}$ $\mathrm{C}$ and at the central region it was $40{ }^{\circ} \mathrm{C}$.

Chart 3: Load versus displacement curve for PET bottle filler slab

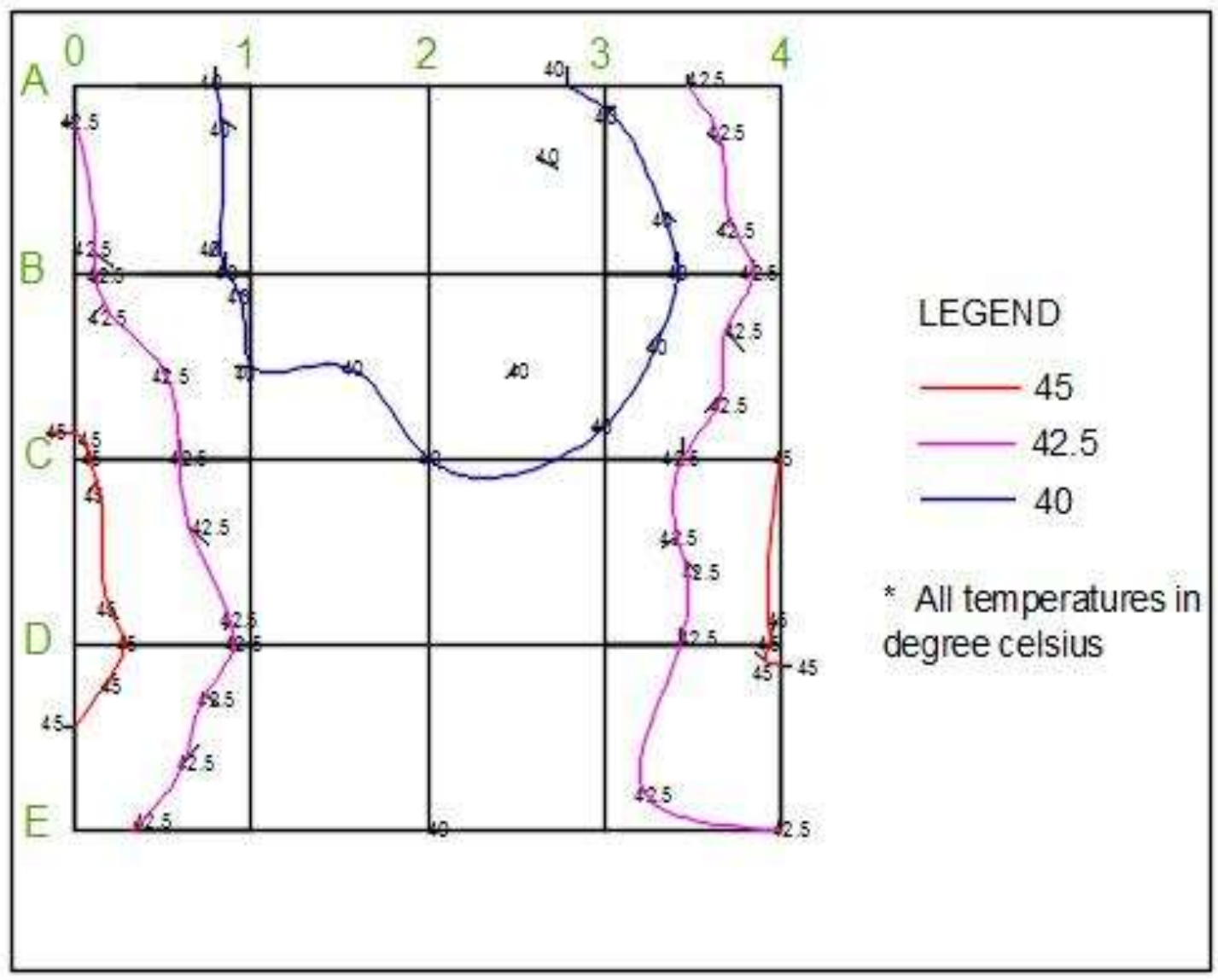

Fig 4: Isotherms for conventional block

In the filler concrete block, coconut shell is placed centrally in the block. The height of the shell affects the insulating property of filler block. The shell forms the cooler region in the block. The initial temperature of the block was found to be $32^{\circ} \mathrm{C}$. After heating the block for 15 minutes, it is seen from that the cooler region is only at the centre of the shell.
The area around the shell has an average temperature of $37.5^{\circ} \mathrm{C}$. However, most of the filler block has an average temperature of $40^{\circ} \mathrm{C}$ and the temperature at corners are found to be $42.5^{\circ} \mathrm{C}$ as shown in figure 5 . 


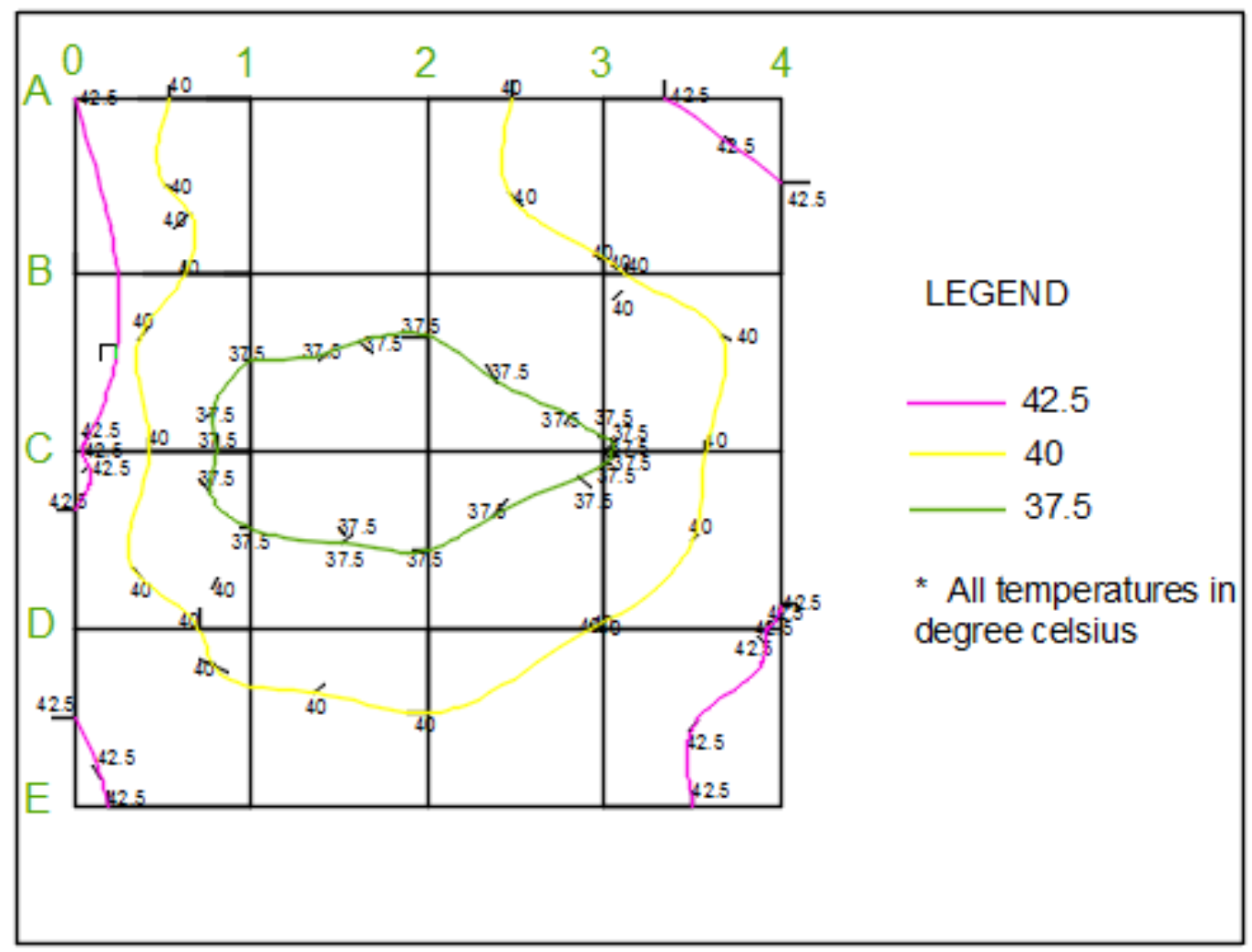

Fig 5: Isotherms for coconut shell filler block

From figure 7 and figure 8 , it can be observed that the highest temperature over the surface of the block was more in conventional concrete block than in filler block.

\subsection{Luminos Ity Test}

The luminosity test is done to check the amount of Illuminance in the form of lux. This was done to check the amount of light passing through the filler cube for different time periods in a day. The comparison was made with the required light levels in different building amenities with the light available due to PET bottles in the slab. This was don e for a standard room dimension of $3 \mathrm{~m} \times 3 \mathrm{~m}$. Upon comparison it was seen that to cater to the required light levels for the dimension of $3 \mathrm{~m} \times 3 \mathrm{~m}$, a slab with 45 PET bottles in it was sufficient as shown in Table 2.

Table 2: Comparison of required light levels and obtained

\begin{tabular}{|l|l|l|l|l|}
\hline & $\begin{array}{l}\text { Min } \\
\text { light } \\
\text { level } \\
\text { lux) } \\
\text { obtained }\end{array}$ & $\begin{array}{l}\text { Min } \\
\text { required } \\
\text { light } \\
\text { level } \\
\text { lux })\end{array}$ & $\begin{array}{l}\text { Max } \\
\text { light } \\
\text { level } \\
\text { lux) } \\
\text { obtained }\end{array}$ & $\begin{array}{l}\text { Max } \\
\text { required } \\
\text { light } \\
\text { level(lux) }\end{array}$ \\
\hline $\begin{array}{l}\text { Lux with only one } \\
\text { opening }\end{array}$ & 9.12 & 50 & 287.28 & 1200 \\
\hline $\begin{array}{l}\text { Lux with 45 } \\
\text { openings }\end{array}$ & 50 & 50 & 1280 & 1200 \\
\hline
\end{tabular}

\section{CONCLUSION}

- It was seen that conventional slab withstood $13 \mathrm{kN}$ more load than the filler slab with coconut shells as filler material and $15 \mathrm{kN}$ more than the filler slab with PET bottles as filler material. This is due to the presence of filler materials in the tension zone of filler slab. The filler slab had a higher bending moment value near the void regions due to weak tension zone.

- The temperature distribution in the conventional concrete block showed isotherms of different temperatures being closely spaced when compared to filler block with coconut shell as filler. The isotherms in filler block were drawn to a maximum temperature of $42.5^{\circ} \mathrm{C}$ and in the conventional concrete block, the isotherms were drawn to a maximum temperature of $45^{\circ} \mathrm{C}$.

- There was an absence of cooler region in the conventional block whereas the area of filler block having the coconut shell had a cooler temperature. This is because, the coconut shell is a poor conductor of heat and thereby provides good thermal insulation to the concrete area around it.

- It was seen from the luminosity test that around $70 \%$ of electricity can be saved by using natural light for 9 hours.

- For half of the working day, light required for the buildings was contributed by natural light with the use of PET filler slab. 


\section{ACKNOWLDEGEMENT}

The author wish to place on record the help provided by the management and the academic teaching and non -teaching faculties of K S School of Engineering and Management, in the completion of this study. We take pleasure in expressing our sincere thanks to Dr. Vijayalakshmi Akella, Professor and Head, Department of Civil Engineering, K.S. School of Engineering and Management, Bengaluru .

\section{REFERENCES}

[1] M.A.D. Chougule, M.M.H. Mota and D.M.U.D.S. Patil, "To Study the Filler Slab as Alternative Construction Technology- A Review", Journal of Information, Knowledge and Research in Civil Engineering, vol. 3, no.2, 2015.

[2] D. Y. Osei, "Experimental assessment on coconut shells as aggregate in concrete," International Journal of Engineering Science Invention, vol. 2, no. 5, May 2013.

[3] Aditya Singh Rawat, R. Kansal, "PET Bottles as Sustainable Building Material: A Step Towards Green Building Construction," Journal of Civil Engineering and Environmental Technology Volume 1, Number 6; August, 2014.

[4] M. K. A. Khafaji, "Experimental and Theoretical Study of Temperature Distribution of High Strength Concrete Exposed To Fire Flame," in The 2nd International Conference of Buildings, Construction and Environmental Engineering (BCEE2), Sharjah, 2015.

[5] D.Sandanasamy, S.Govindarajane, T.Sundararajan, "Natural Lighting in Green Buildings -An Overview and a Case Study," International Journal of Engineering Science and Technology (IJEST) Vol. 5 No.01 January 2013. 